\title{
Evaluation of Postprandial Glycemic Response and Physical Properties of High-Amylose Rice "Koshinokaori"
}

\author{
Tomoko YAMAGUCHI $^{1}$, Yasuaki ENOKI ${ }^{2}$, Katsumi SASAGAWA ${ }^{2}$ and Shinobu FuJIMURA ${ }^{3}$ \\ ${ }^{1}$ Faculty of Education, Niigata University, 8050 Ikarashi 2-no-cho, Nishi-ku, Niigata 950-2181, Japan \\ ${ }^{2}$ Bourbon, Institutes of Health, 316-2 Higashijima, Akiha-ku, Niigata 956-0841, Japan \\ ${ }^{3}$ Faculty of Agriculture, Niigata University, 8050 Ikarashi 2-no-cho, Nishi-ku, Niigata 950-2181, Japan
}

\begin{abstract}
Summary This study evaluated the postprandial glycemic response and physical properties of the high-amylose rice, Koshinokaori (KK), cooked under different conditions. Twelve healthy subjects (Japanese, 6 males, 6 females) were given cooked, white KK rice or tomato chicken rice (TCR) using KK rice. The Japanese standard rice, Koshihikari (KH), was used as reference. All meals contained the same amount $(50 \mathrm{~g})$ of available carbohydrate. Blood glucose levels were measured at 0 (fasting), 15, 30, 45, 60, 90, and 120 min after each meal. The results from the cooked, white KK rice showed a significant difference in blood glucose variation at 60, 90, and $120 \mathrm{~min}$ and the incremental area under the curve (IAUC) of blood glucose concentration for KK cooked at optimal water to rice ratio was observed. Blood glucose variation and IAUC after intake of TCR-KK rice was lower than that after TCR-KH rice intake. Addition of $5 \%$ trehalose to KK rice resulted in a smaller decrease in adhesiveness and stickiness of cooked rice after $180 \mathrm{~min}$ at $20^{\circ} \mathrm{C}$. The addition of $5 \%$ trehalose to $\mathrm{KK}$ rice also produced favorable results in the sensory evaluation. KK rice produces favourable postprandial glycemic responses and physical properties under varied cooking condition and thus, may be beneficial in the prevention of lifestyle-related diseases such as type 2 diabetes. Key Words high-amylose rice, Koshinokaori, postprandial glycemic response, physical properties
\end{abstract}

Rice is a major staple crop in Asian countries, especially in Japan. Rice accounts for about 30\% of the total energy intake and a half of the carbohydrate intake of Japanese people. However, epidemiological studies have reported that ingesting white rice raises the risk of type 2 diabetes $(1,2)$. In 2016, 20 million people in Japan were reported to suffer from diabetes (3). Diabetes is a lifestyle-related disease that can have serious complications, such as cardiovascular disease, nephropathy, cataracts, and dementia. Dietary control of blood glucose levels plays a key role in managing diabetes.

Rice is typically considered a highly digestible source of carbohydrate, but the rate of digestion and the resulting glycemic response varies among rice cultivars and preparation techniques $(4,5)$. The amylose content of rice affects glycemic responses due to the tendency of amylose to retain its crystalline structure after cooking. This reduces enzyme accessibility and results in a greater proportion of slowly digestible and resistant starch.

Studies focusing on the role of rice amylose content in reducing the risk of diabetes have reported that highamylose rice produces mild increases in blood glucose levels after meals (6-8). Several high-amylose, short grain rice varieties, similar to Japanese domestic rice, have been developed in recent years. Hokuriku 207 rice variety incorporated the high-amylose properties of the Indian rice variety, Surjamukhi, into Kinuhikari and was

E-mail: tomokoy@ed.niigata-u.ac.jp registered as "Koshinokaori" in 2011 (9). Koshinokaori (KK), a short grain variety, solved problems related to the polishing suitability of high-amylose rice, but undesirable texture and rapid retrogradation when cooked were major disadvantages. The texture of cooked rice is an extremely important attribute for acceptance of rice variants (10). The texture of cooked rice is affected by multiple factors, including the composition of amylose and amylopectin, cooking method, and preservation conditions (11-13).

Our previous study reported that to produce desirable physical properties and favorable sensory evaluation, the optimal cooking conditions for KK involved a high water to rice ratio (13). However, postprandial glycemic responses and retrogradation of cooked rice may be affected by rice cooking conditions. In this study, we investigated postprandial glycemic responses to white KK rice and tomato chicken KK rice when cooked using the optimal water to rice ratio. Suppression of retrogradation of KK rice by adding trehalose, which has been reported to suppress retrogradation of starch was also examined.

\section{Materials and Methods}

Materials. High-amylose KK rice (test rice) and intermediate-amylose, Japanese standard KH rice (reference rice) were used. Both rice varieties were cultivated and polished in Niigata, Japan. The amylose content of KK and KH were $26.3 \%$ and $16.6 \%$, respectively. 
Experiment 1: Glycemic response

(1) Test meals. Four meals were tested. In Experiment 1-1, two types of cooked white rice, and two kinds of tomato chicken rice (TCR) were subjected to Experiment 1-2. Test and reference meals were given to the subjects under a single blind, crossover design with a washout period of at least $1 \mathrm{wk}$.

In Experiment 1-1, the meals were prepared in the following manner: rice was soaked in water for $30 \mathrm{~min}$ at $20^{\circ} \mathrm{C}$ then cooked in an electric rice cooker (NP-BC10, Zojirushi, Japan) with a water to rice ratio of 1.4:1 for $\mathrm{KH}(\mathrm{KH} 1.4)$ and 2.2:1 for KK (KK2.2).

In Experiment 1-2, TCR made with $\mathrm{KH}$ rice (TCR$\mathrm{KH}$ ) and TCR made with KK (TCR-KK) were prepared in the following manner: 1 cup $(150 \mathrm{~g})$ of rice was soaked in water $\left(170 \mathrm{~mL} /\right.$ cup rice) for $30 \mathrm{~min}$ at $20^{\circ} \mathrm{C}$. Then, mushroom ( $25 \mathrm{~g} / \mathrm{cup}$ rice), chicken breast meat (65 g/cup rice), butter ( $5 \mathrm{~g} /$ cup rice), soup stock powder ( $5.3 \mathrm{~g} /$ cup rice), tomato ketchup (22.5 g/cup rice) and salt-free tomato juice $(100 \mathrm{~mL} /$ cup rice) were added and cooked in a rice cooker (NP-BC10, Zojirushi, Japan).

(2) Study protocol. In experiment 1-1, 12 healthy subjects (Japanese, 6 males, 6 females, aged 21.3 $\pm 1.1 \mathrm{y}$, BMI $20.9 \pm 1.8 \mathrm{~kg} / \mathrm{m}^{2}$ ) participated. In experiment $1-2$, 12 healthy subjects (Japanese, 6 males, 6 females, aged $21.3 \pm 1.1 \mathrm{y}$, BMI of $19.5 \pm 1.9 \mathrm{~kg} / \mathrm{m}^{2}$ ) participated. After $11 \mathrm{~h}$ fasting, subjects consumed a reference or test meal containing $50 \mathrm{~g}$ available carbohydrate. All meals were taken over $10 \mathrm{~min}$ with $200 \mathrm{~mL}$ of water. Finger-prick blood samples were collected with Medisafe ${ }^{\circledR}$ finetouch II (Terumo Corporation, Tokyo, Japan) at 0 (fasting), 15, 30, 45, 60, 90, and 120 min after starting the meal. Blood glucose was measured using a Medisafe FIT $^{\circledR}$ (Terumo Corporation, Tokyo, Japan). Blood glucose variation was determined by subtracting the fasting blood glucose level from the postprandial blood glucose level. Incremental area under the curve (IAUC) was calculated using the trapezoid rule (14), ignoring the area below baseline.

In Experiment 1-2, sensory evaluation (appearance, smell, taste, sweetness, stickiness, hardness, and overall evaluation) was carried out using a 7 point scale (where $3=$ extremely like and $-3=$ extremely dislike) along with the measurement of blood glucose levels, described above.

The study was approved by the research ethics committee of Niigata University (approval number: 2017-2007) and was conducted in accordance with the Declaration of Helsinki.

Experiment 2: physical properties of cooked rice

(1) Sample preparation. KK rice was soaked in water with or without $5 \%$ trehalose (Hayashibara Co., Ltd.) for $30 \mathrm{~min}$ at $20^{\circ} \mathrm{C}$, then cooked in an electric rice cooker (NP-PE10, Zojirushi, Japan) with a water to rice ratio of 1.4:1 or $2.2: 1$.

(2) Measurement of physical properties. The physical properties (hardness, strength, adhesiveness, and stickiness) of cooked rice were measured using a Tensipresser (TTP-50BX II, Taketomo Electric Inc., Japan) at $20^{\circ} \mathrm{C}$ at 30, 60, 120, and $180 \mathrm{~min}$ after cooking. Measurement

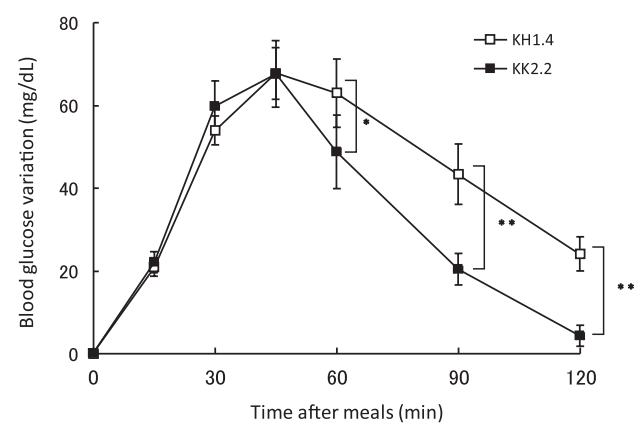

Fig. 1. Blood glucose variation after intake of cooked white rice. KH1.4: Koshihikari rice cooked 1.4:1, water to rice; KK2.2: Koshinokaori rice cooked 2.2:1, water to rice. Data represents mean \pm SE of 12 subjects. $* p<0.05,{ }^{* *} p<0.01$.

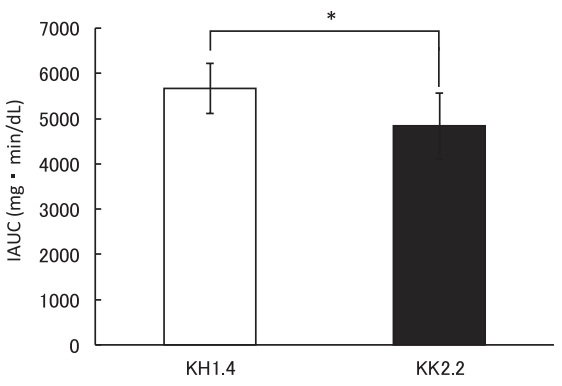

Fig. 2. IAUC for blood glucose after intake of cooked white rice. KH1.4: Koshihikari rice cooked 1.4:1, water to rice; KK2.2: Koshinokaori rice cooked 2.2:1, water to rice. Data represents mean \pm SE of 12 subjects. ${ }^{*} p<0.05$.

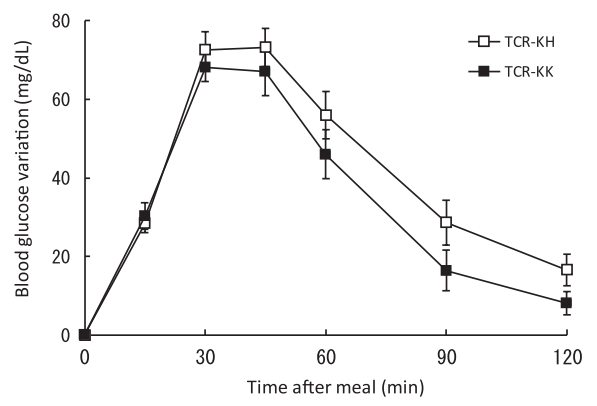

Fig. 3. Blood glucose variation after intake of tomato chicken rice. TCR-KH: tomato chicken rice using Koshihikari; TCR-KK: tomato chicken rice using Koshinokaori. Data represents mean \pm SE of 12 subjects.

conditions were as described previously (13).

(3) Sensory evaluation. KK rice cooked with a water to rice ratio of 2.2:1 was used for sensory evaluation and KK rice with 5\% trehalose (KK2.2-5\%) was evaluated against KK without trehalose (KK2.2-0\%). The sensory evaluation was performed in the same manner as in Experiment 1-2. Participants were 26 female students of Niigata University aged 21.0 $\pm 1.1 \mathrm{y}$.

Statistical analysis. Data were analyzed using Ekuseru-Toukei 2012 v1.10 (Social Survey Research Information, Japan). Physical properties are expressed as 


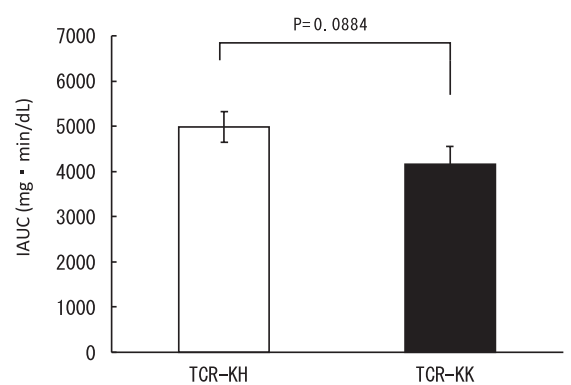

Fig. 4. IAUC for glucose after intake of tomato chicken rice. TCR-KH: tomato chicken rice using Koshihikari; TCR-KK: tomato chicken rice using Koshinokaori. Data represents mean \pm SE of 12 subjects.

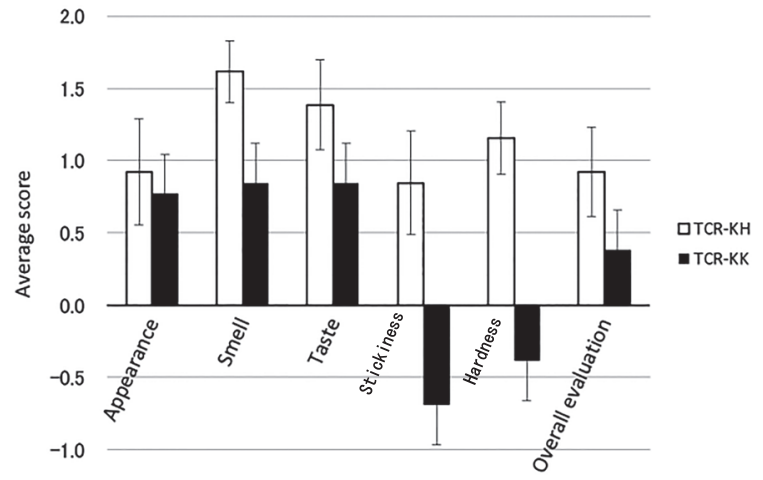

Fig. 5. Sensory evaluation of tomato chicken rice. TCRKH: tomato chicken rice using Koshihikari; TCR-KK: tomato chicken rice using Koshinokaori. Data represents mean \pm SE of 12 subjects. ${ }^{*} p<0.05,{ }^{* *} p<0.01$.

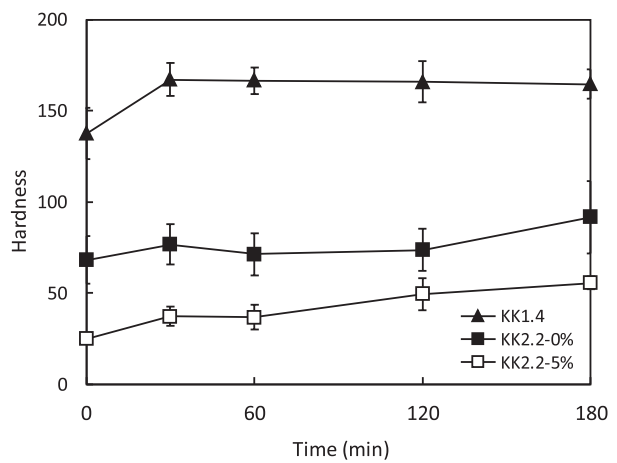

Fig. 6. Change in the hardness of cooked rice with or without 5\% trehalose. KK1.4: Koshinokaori rice cooked $1.4: 1$, water to rice; KK2.2-0\%: Koshinokaori rice cooked 2.2:1, water to rice; KK2.2-5\%: Koshinokaori rice cooked 2.2:1, water to rice with 5\% trehalose. Data represents mean $\pm \mathrm{SD}, n=3$.

mean \pm SD, and the other results expressed as mean \pm SE. The effect of treatment on IAUC and sensory evaluation was calculated by paired $t$-test. Effects of treatment, time and their interaction on blood glucose variation were analyzed using two-way repeated-measures ANOVA, followed by Tukey's post hoc test. When a treatment effect was observed, significance at each time point were carried out with the use of paired $t$-test. $p<0.05$ was considered statistically significant.

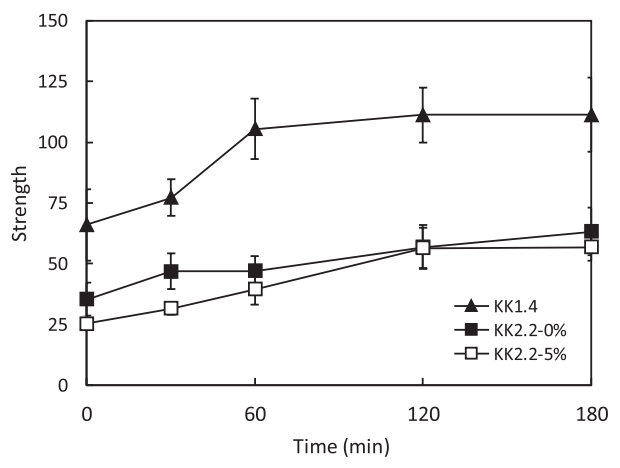

Fig. 7. Change in the strength of cooked rice with or without 5\% trehalose. KK1.4: Koshinokaori rice cooked 1.4:1, water to rice; KK2.2-0\%: Koshinokaori rice cooked 2.2:1, water to rice; KK2.2-5\%: Kishinokaori rice cooked 2.2:1, water to rice with 5\% trehalose. Data represents mean $\pm \mathrm{SD}, n=3$.

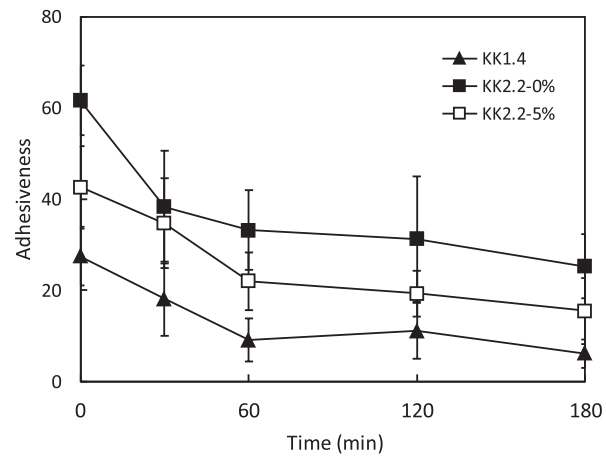

Fig. 8. Change in the adhesiveness of cooked rice with or without $5 \%$ trehalose. KK1.4: Koshinokaori rice cooked 1.4:1, water to rice; KK2.2-0\%: Koshinokaori rice cooked 2.2:1, water to rice; KK2.2-5\%: Koshinokaori rice cooked 2.2:1, water to rice with 5\% trehalose. Data represents mean $\pm \mathrm{SD}, n=3$.

\section{Results}

Glycemic response to cooked white rice

Blood glucose variation were affected by treatment $(p<0.05)$ and time $(p<0.01)$, but there was no treatment and time interaction $(p=0.0595)$. Blood glucose variation after KK2.2 versus KH1.4 intake was significantly lower at 60, 90, and $120 \mathrm{~min}$ (Fig. 1). IAUC after KK2.2 intake was significantly lower than after KH1.4 intake $(p<0.05)$ (Fig. 2).

Glycemic response to tomato chicken rice

Blood glucose variation were affected by treatment $(p<0.05)$ and time $(p<0.01)$, but there was no treatment and time interaction $(p=0.7517)$. Blood glucose variation (Fig. 3) after TCR-KK intake were lower than those after TCR-KH intake, but no significant difference was found between the treatment meals at each time point. IAUC after TCR-KK intake tended to be lower than after TCR-KH intake ( $p=0.0884$ ) (Fig. 4).

Sensory evaluation of tomato chicken rice

Sensory evaluation of TCR-KK was significantly lower than that TCR-KH in terms of smell, stickiness, and hardness. However, no significant differences between 


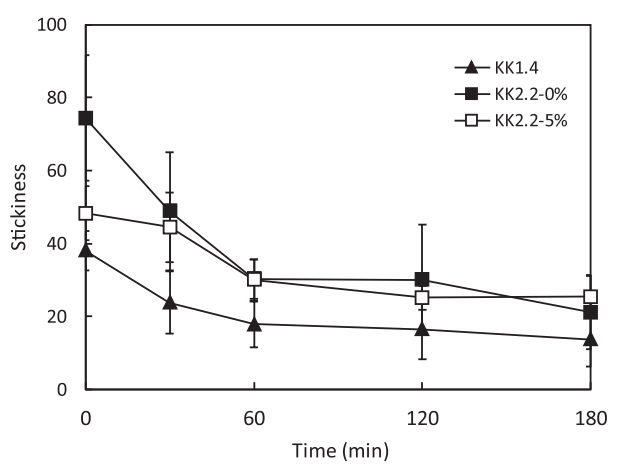

Fig. 9. Change in the stickiness of cooked rice with or without 5\% trehalose. KK1.4: Koshinokaori rice cooked 1.4:1, water to rice; KK2.2-0\%: Koshinokaori rice cooked 2.2:1, water to rice; KK2.2-5\%: Koshinokaori rice cooked 2.2:1, water to rice with $5 \%$ trehalose. Data represents mean $\pm \mathrm{SD}, n=3$.

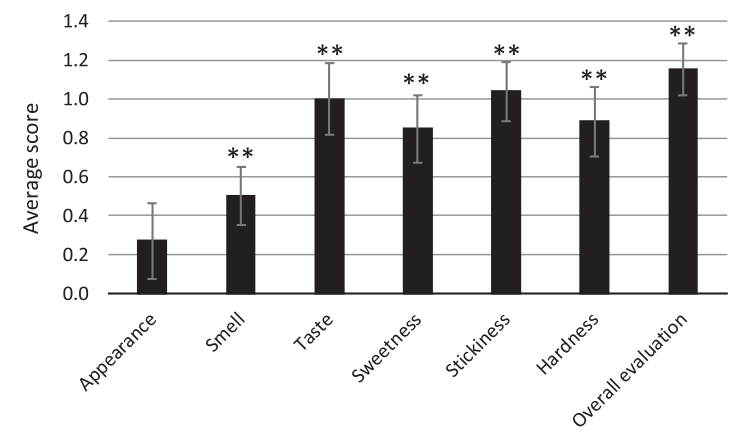

Fig. 10. Sensory evaluation of Koshinokaori rice with $5 \%$ trehalose. Mean \pm SE, $n=26 .{ }^{* *} p<0.01$ compared to scores for Koshinokaori rice with no trehalose.

TCR-KH and TCR-KK were observed for appearance, taste, and overall evaluation (Fig. 5).

Physical properties of cooked rice

Changes in the physical properties of cooked KK rice were measured over a $180 \mathrm{~min}$ period after cooking. The highest values for hardness (Fig. 6) and strength (Fig. 7) were observed in KK1.4. Conversely, the lowest values of adhesiveness and stickiness were also observed in KK1.4. Hardness, strength, adhesiveness, and stickiness values for KK2.2-5\% were all lower than those of KK2.2-0\% (Fig. 6, 7, 8, and 9, respectively). Interestingly, addition of $5 \%$ trehalose during cooking was seen to reduce the decrease in adhesiveness and stickiness of rice over the 180 min measurement period (see KK2.2$5 \%$, Fig. 8 and 9).

Sensory evaluation of cooked rice

Significant differences were observed in smell, taste, sweetness, stickiness, and hardness of KK2.2-5\% compared with KK2.2-0\% $(p<0.01)$ (Fig. 10). In addition, KK $2.2-5 \%$ was preferred in terms of overall evaluation $(p<0.01)$.

\section{Discussion}

Several studies have assessed the glycemic response of high-amylose rice (6-8). In the present study, we evalu- ated both postprandial glycemic responses and the physical properties of high-amylose rice, KK, cooked under different conditions. This open-blind, crossover study was designed to investigate the effect of KK on postprandial glycemic responses compared to intermediate-amylose, conventional rice, $\mathrm{KH}$, in healthy subjects. Results examining cooked white rice showed a significant difference in blood glucose variation and IAUC in subjects after consuming KK versus KH rice cooked at the optimal water to rice ratio. In previous research by our group, a significant difference in blood glucose variation was observed only at $15 \mathrm{~min}$ after intake of packed KK rice using a water rice ratio of 1.3:1 (8). Panlasigui et al. (4) reported that not only does the amylose content of starch influence the blood glucose response, but the physicochemical properties (gelatinization), too. These results suggest that cooking conditions, and not only the amylose content of rice, are an important factor affecting glycemic responses.

Results from the sensory evaluation of tomato chicken rice showed no significant differences between TCR-KH and TCR-KK with regard to appearance, taste, and overall evaluation. Therefore, TCR-KK is considered comparatively acceptable for a daily meal. The effect of tomato chicken rice cooking on glycemic response were significantly different among rice samples. However, there was no significant difference in blood glucose variation at each blood sampling point. It has been reported that some food ingredients suppress the glycemic response at the time of carbohydrate intake. For example, it has been reported that proteins and lipids moderate increases in blood glucose levels by moderating the excretion of stomach contents (15). Because tomato chicken rice contained chicken and butter in addition to white rice, ingredients other than amylose, such as proteins, may have impacted on glycemic responses.

With regard to the physical properties of cooked rice, the initial hardness and strength values of KK2.2-0\% were lower than those of KK1.4, while the initial value of adhesiveness and stickiness of KK2.2-0\% was higher than those of KK1.4. The water content of KK1.4 and KK2.2-0\% were $57.3 \%$ and $69.3 \%$, respectively (13). Cooking with a higher amount of water improved the physical properties of KK. However, it is likely that the increase water to rice ratio effected the retrogradation of the cooked rice.

Trehalose is a non-reducing disaccharide composed of two $\alpha$-(D)-glucose units linked together by a 1, 1-glycosidic linkage. This saccharide has many useful functions; sweetening, low-damage to nutrients, and prevention of starch retrogradation, protein denaturation and lipid degradation. Hirata (16) reported the effects of trehalose on the texture of cooked KH rice. Area efficiency, a physical property indicator, increased with the addition of $2-4 \%$ trehalose. However, area efficiency decreased with the addition of $5 \%$ trehalose or more, to become similar to rice without trehalose. Area efficiency reached a maximum with the addition of 3\% trehalose, and changes in rice texture during storage at $20^{\circ} \mathrm{C}$ were less when trehalose was added, as compared to rice 
without trehalose. In the present study it was found that the decrease in adhesiveness and stickiness of $\mathrm{KK}$ rice cooked with $5 \%$ trehalose after $180 \mathrm{~min}$ at $20^{\circ} \mathrm{C}$ was reduced. In addition, positive results were also obtained from the sensory evaluation of KK rice with the addition of $5 \%$ trehalose during cooking.

Rice is often cooked with oil and various seasonings. Ito et al. (17) reported the effect of seasonings such as salt, soy sauce, sugar, vinegar, alcohol, and tomato paste during cooking on the properties of rice, while Hibi (18) has investigated the effect of addition of oil on the retrogradation of cooked rice. However, both studies involved Japanese standard rice, thus the effect of oil and seasoning on high-amylose rice, such as KK, is not clear. Further studies are required to determine the effect of additive foods on the physical properties and glycemic response to $\mathrm{KK}$.

In conclusion, the present study suggests that KK can attenuate postprandial glycemic responses, even when the cooking method is changed. Furthermore, addition of trehalose not only improved taste, but suppressed the retrogradation of cooked rice. Thus, the consumption of KK rice may be useful for the prevention of lifestylerelated diseases such as type 2 diabetes.

\section{Disclosure of State of COI}

Yasuaki Enoki and Katsumi Sasagawa are employees of Bourbon Corporation.

\section{Acknowledgments}

This study was supported by the project for the promotion of regional and industrial development in supporting healthy eating habits, the Ministry of Agriculture, Forestry and Fisheries, Japan. The authors thank the students of Niigata University for their cooperation in this research. We express our gratitude to Ms. Masumi Kobayashi, Makoto Mizutani, and Kana Nannichi for their cooperation.

\section{REFERENCES}

1) Nanri A, Mizoue T, Noda M, Takahashi Y, Kato M, Inoue M, Tsugane S. 2010. Rice intake and type 2 diabetes in Japanese men and women: the Japan Public Health Center-based prospective study. Am J Clin Nutr 92: 1468-1477.

2) Hu EA, Pan A, Malik V, Sun Q. 2012. White rice consumption and risk of type 2 diabetes: meta-analysis and systematic review. BMJ 344: e1454.

3) Ministry of Health, Labour and Welfare. 2017. National Health and Nutrition Survey. https://www.mhlw.go.jp/ stf/houdou/0000177189.html (accessed 15.12.2018).

4) Panlasigui, LN, Thompson LU, Juliano BO, Perez CM, Yiu SH, Greenberg GR. 1991. Rice varieties with similar amylose content differ in starch digestibility and glycemic response in humans. Am J Clin Nutr 54: 871-877.

5) Brand-Miller JC, Stockmann K, Atkinson F, Petocz P, Denyer G. 2009. Glycemic index, postprandial glycemia, and the shape of the curve in healthy subjects: Analysis of a database of more than 1000 foods. Am J Clin Nutr 89: 97-105.

6) Zenel AM, Stewart ML. 2015. High amylose white rice reduces post-prandial glycemic response but not appetite in humans. Nutrients 7: 5362-5374.

7) Goddard MS, Young G, Marcus R. 1984. The effect of amylose content on insulin and glucose responses to ingested rice. Am J Clin Nutr 39: 388-392.

8) Mori H, Mori M, Ikuta Y, Enoki Y, Sasagawa K, Tanaka S, Kida N, Nomura T, Yamori Y. 2018. Effect of different rice cooking conditions on glycemic response of Japanese high amylose rice variety "Koshinokaori": a double-blind, randomized, crossover study. Nihon Byotai Eiyo Gakkaishi (J Metabol Clin Nutr) 21: 237-246 (in Japanese).

9) Sasahara H, Miura K, Shimizu H, Goto A, Shigemune A, Nagaoka I, Uehara Y, Kobayashi A, Ohta H, Fukui K, Otsuki H, Yano M, Komaki Y. 2013. 'Koshinokaori,' a new rice noodle cultivar. Chūō Nōgyō Sōgō Kenkyū Sentā Kenkyū Hōkoku (Bull NARO Agric Res Cent) 19: 15-29 (in Japanese).

10) Yanagimoto M. 2002. Comparison of sensory characteristics in their contribution to food palatability. Nihon Chourikagaku Kaishi (J Cookery Sci Jpn) 35: 32-36 (in Japanese).

11) Suzuki K, Okadome H, Nakamura S, Ohtsubo K. 2006. Quality evaluation of various "New Characteristic Rice" varieties based on physicochemical measurements. Nippon Shokuhin Kagaku Kogaku Kaishi (J Jpn Soc Food Sci Technol) 53: 287-295 (in Japanese).

12) Ohya C, Kawabata A. 1998. The taste characteristics of rice with different varieties. Nippon Shokuhin Kagaku Kogaku Kaishi (J Jpn Soc Food Sci Technol) 45: 341-348 (in Japanese).

13) Enoki Y, Sasagawa K, Fujimura S, Yamaguchi T. 2018. Investigation of optimal water addition ratio on rice cooking of high-amylose rice "Koshinokaori". Nippon Shokuhin Kagaku Kogaku Kaishi (J Jpn Soc Food Sci Technol) 65: 313-317 (in Japanese).

14) Flint A, Møller BK, Raben A, Pedersen D, Tetens I, Holst JJ, Astrup A. 2004. The use of glycaemic index tables to predict glycaemic index of composite breakfast meals. $\mathrm{Br}$ J Nutr 91: 979-989.

15) Hätönen KA, Virtamo J, Eriksson JG, Sinkko HK, Sundvall JE, Valsta LM. 2011. Protein and fat modify the glycaemic and insulinaemic responses to a mashed potatobased meal. Br J Nutr 106: 248-253.

16) Hirata K. 2009. Effects of trehalose on texture of cooked rice. Hiroshima Kenritu Sōgō Gizyutu Kenkyūzyo Syokuhin Kōgyō Gizyutu Sentā Kenkyū Hōkoku (Bulletin of Hiroshima Prefectural Technology Research Institute Food Technology Research Center) 25: 1-4 (in Japanese).

17) Ito J, Kasai M, Kainuma Y, Hatae K. 2004. The effect of the various seasonings on cooking properties of rice (Part 1). Nippon Shokuhin Kagaku Kogaku Kaishi (J Jpn Soc Food Sci Technol) 51: 531-538 (in Japanese).

18) Hibi Y. 1993. Effect of addition of oil on the retrogradation of cooked rice. Nihon Kasei Gakkaishi (J Home Econ Jpn) 44: 471-476 (in Japanese). 